\title{
Peripheral Cemento-Ossifying Fibroma with Uncommon Clinical Presentation: A Case Report
}

\section{Fibroma periférico cemento-ossificante con una presentación clínica poco común: Reporte de caso}

Suresh K. Sachdeva M.D.S.1; Sakshi Mehta B.D.S.2; Husain Sabir M.D.S. ${ }^{3 ;}$ Purnendu Rout M.D.S. ${ }^{4}$

1. Reader, Department of Oral Medicine and Radiology, Surendera Dental College and Research Institute, SriGanganagar-335001, Rajasthan, India.

2. Post graduate student, Department of Oral Medicine and Radiology, Surendera Dental College and Research Institute, SriGanganagar-335001, Rajasthan, India.

3. Consultant Oral Physician and Radiologist, Raj Multispecialty Dental Clinic, Indore, India.

4. Reader, Department of Oral Medicine and Radiology, Kalinga Institute of Dental Sciences, Bhubaneswar, Odisa.

Correspondence to: Dr. Suresh K. Sachdeva - drsureshsachdeva7184@gmail.com

Received: 9-VIII-2017

Accepted: 17-X-2017

Published Online First: 23-X-2017

D0I: https://doi.org/10.15517/ijds.v0i0.31007

\section{ABSTRACT}

Peripheral cemento-ossifying fibroma (PCOF) is a reactive gingival over growth, occurring frequently in the maxillary anterior region of teenage and young females. Peripheral cemento-ossifying fibroma (PCOF) is supposed to be originating from periosteum and/or periodontal ligament. A large number of factors have been implicated in the pathogenesis of PCOF, which includes trauma, local irritation, calculus and hormonal disturbances. The definitive diagnosis of PCOF is based upon its clinical, radiological and histological features. Because of the high recurrence rate (8-20\%) of PCOF, a close post-operative follow-up is required. Herewith, we are presenting a case of PCOF in 24-year old female patient at an uncommon location.

\section{KEYWORDS}

Cemento; Fibroma; Mandible; Ossifying; Peripheral; Reactive lesion. 


\section{RESUMEN}

El fibroma cemento-osificante periférico (PCOF, por sus siglas en inglés) es un crecimiento gingival reactivo, que se produce con frecuencia en la región anterior del maxilar en adolescentes y mujeres jóvenes. Se supone que el fibroma cemento-osificante periférico (PCOF) se origina en el periostio y/o el ligamento periodontal. Una gran cantidad de factores han sido implicados en la patogénesis de PCOF, dentro de las que se incluye trauma, irritación local, cálculo y alteraciones hormonales. El diagnóstico definitivo de PCOF se basa en sus características clínicas, radiológicas e histológicas. Debido a la alta tasa de recurrencia (8-20\%), se requiere un seguimiento post-operatorio estricto. Mediante este artículo presentamos un caso de PCOF en una paciente de 24 años de edad y el manejo teraupético.

\section{PALABRAS CLAVE}

Cemento; Fibroma; Mandíbula; Lesión reactiva.

\section{INTRODUCTION}

PCOF is common gingival growth that is thought to be either reactive or neoplastic in nature, accounting for about $3.1 \%$ of all oral tumors and $9.6 \%$ of gingival lesions (1). The World Health Organization (1992) classification groups under a single designation (cemento-ossifying fibroma) two histologic types (cementifying fibroma and ossifying fibroma) that may be clinically and radiographically indistinguishable. These lesions may form as a result of irritants such as trauma, plaque, calculus, dental restorations dental appliances, and microorganism. PCOF is a bone producing, slow growing, asymptomatic, well demarcated, benign lesion of the jaw (2). It may occur at any age, but exhibits a peak incidence between the second and third decades (3). Clinically PCOF's are sessile or pedunculated, usually ulcerated and erythematous or exhibiting a color similar to the surrounding gingiva. Most lesions are $<2 \mathrm{~cm}$ in size, although larger lesions occasionally occur. Most of the PCOF occurs in maxillary arch $(60 \%)$ with predilection for incisor, cuspid region (>50\%) (4). A potential for tooth migration due to the presence of PCOF has been reported. In general, there is no apparent underlying bone involvement on radiographs. But occasionally, there appears to be superficial erosion of bone. PCOF should be surgically excised and submitted to microscopic examination for confirmation of diagnosis. Recurrence rate is reported between $8-20 \%$ (5). The aim of this article is to report a case of PCOF, reported in female patient, in mandibular anterior region, making it uncommon presentation.

\section{CASE REPORT}

A 24-year old female reported to the department of Oral Medicine \& Radiology, with a chief complaint of painless growth on gums in lower left front teeth region since last 2 years. History revealed that the growth was initially small in size but from past 7 months, it gradually increased to attain present size. There was history of occasional bleeding during mastication, tooth brushing and spitting, leading to salty taste in the mouth. There was no history of past trauma, chronic irritation, recent weight loss, systemic rise in temperature, parasthesia/numbness and similar growth elsewhere in the body. The Past dental/medical history was non contributory. The general physical examination revealed that all the vital signs were within normal limits. No gross facial asymmetry was appreciated on extra oral examination. (Figure 1a) The intraoral examination revealed a well circumscribed, solitary, oval shaped, erythematous \& pedunculated growth 
present on labial gingiva involving interdental papilla between $31,32,33$. The growth extended antero-posteriorly from mesial aspect of 31 to distal surface of 33 and superiorly up to middle of coronal portion of 31, 32, 33 with approximate size of $1.5 \times 2 \mathrm{~cm}$. The overlying mucosa of growth appeared rough, lobulated, pinkish in color with interspersed reddish areas. (Figure 1b) On palpation, the growth was firm to hard, non-tender. On probing, pseudo pockets were found irt 31,32 , 33. No discharge on palpation from growth was seen. Calculus was present between 31, 32, 33 teeth. On the basis of history \& clinical examination, a provisional diagnosis gingival epulis was made. The differential diagnosis considered was traumatic firoma, pyogenic granuloma, Peripheral fibroma with calcification, Peripheral Cemento-ossifying fibroma, and Peripheral giant cell granuloma. The intraoral periapical radiograph 31, 32, 33, 41 and orthopantomographic (OPG) examination showed no obvious bony changes. (Figure $2 \mathrm{a} \& \mathrm{~b}$ ). All the hematological reports were in normal limits. Later with patient consent, excision of the lesion was done under local anesthesia (Figure 3) and the specimen was sent for histopathological examination, which showed parakeratinzed stratified squamous epithelium of variable thickness with evidence of ulceration in some areas. The underlying dense fibrous connective tissue shows varying degrees of cellularity along with foci of mineralization. The hard tissue component showed basophillic acellular spherules. There was presence of focal chronic inflammatory cell infiltrate and granulation tissue formation in some areas. These features were suggestive of peripheral cemento-ossifying fibroma. (Figure 4) In the present case, after excision of the lesion, all the remnant of the lesion was removed and thorough debridement was done. Capsule amoxicillin $(500 \mathrm{mg})$, tablet metronidazole (400mg) and tablet ibuprofen $(400 \mathrm{mg})$ were prescribed to the patient thrice daily for five day postoperatively, to relieve the pain and to prevent secondary infection Following this, close monitoring was done after 10 days, 1 month, 3 months and 6 months and no recurrence was observed. The surgical site appeared to be healing well. The patient was asymptomatic, aesthetically sound and satisfied with results on follow up.

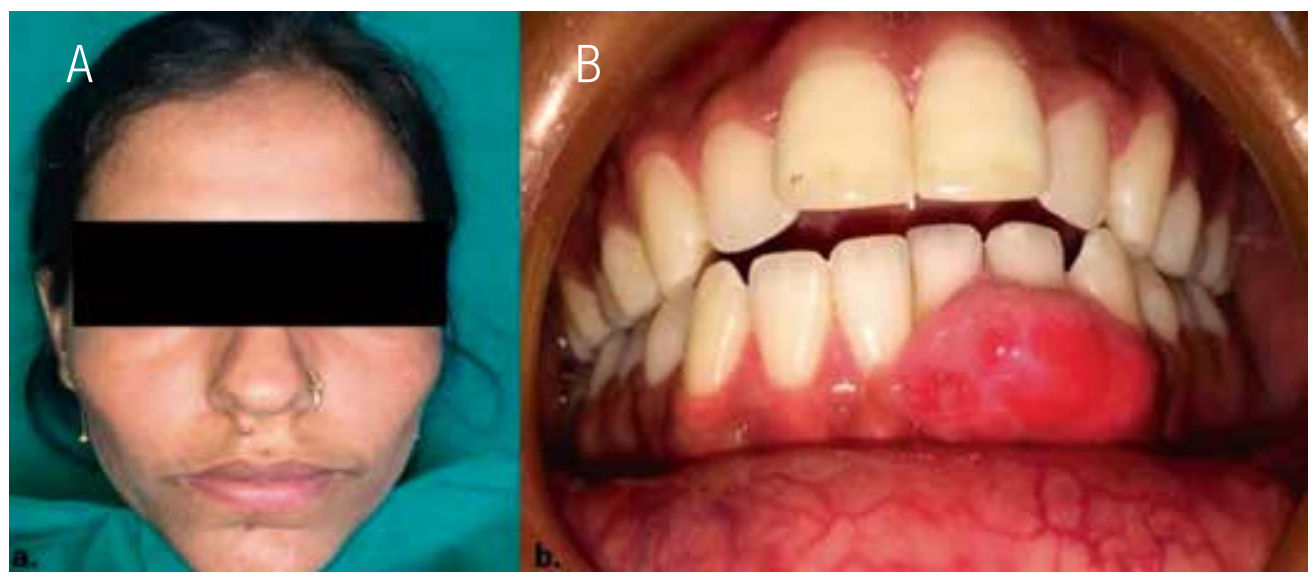

Figure 1. Extra oral photograph with no facial asymmetry $(1 \mathrm{~A})$ and intraoral photograph of the growth (1B). 

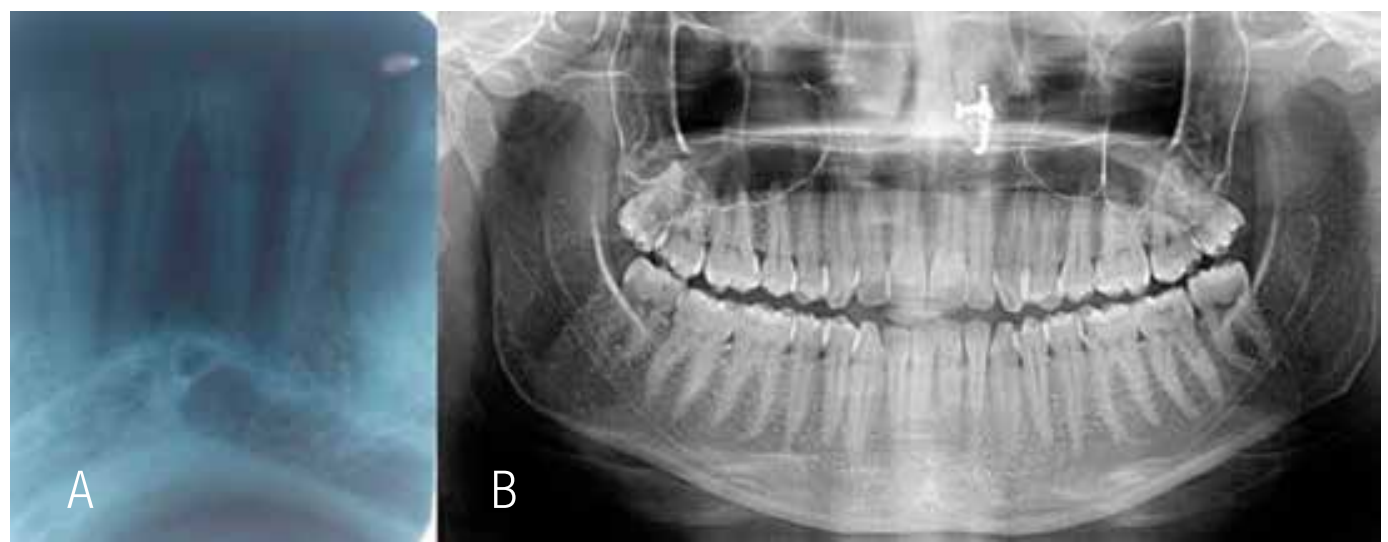

Figure 2. Intraoral periapical radiograph (2A) and Orthopantomograph (2B) of the lesion showing no apparent change in the bone.

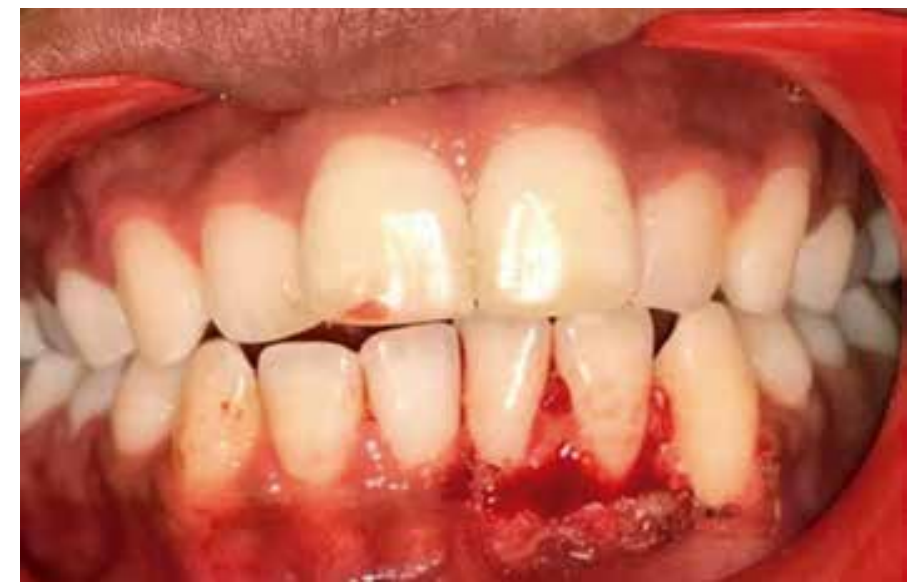

Figure 3. Intra oral photograph of the same region just after the excision of the lesion.

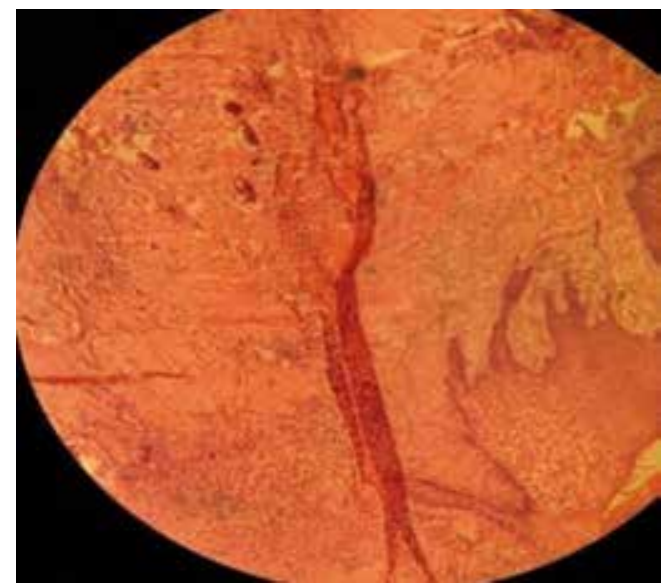

Figure 4. Photomicrograph of the lesion showing features of cemento-ossifying fibroma. ( $\mathrm{H} \& \mathrm{E}, \mathrm{x} 10)$. 


\section{DISCUSSION}

Peripheral cemento-ossifying fibroma (PCOF) is a well-demarcated, focal, reactive, non-neoplastic tumor-like growth of soft tissue, arising from the interdental papilla. The World Health Organization (WHO) classifies cemento-ossifying fibroma as a fibroosseous neoplasm, while the term "cementifying" has been used when curvilinear trabeculae or spheroidal calcifications are seen. When bone and cementum like tissues are observed, the lesions have been referred to as cementoossifying fibroma (6). PCOF is derived from the mesenchymal cells of the periodontal ligament, with a potential to form fibrous tissue, cementum and bone, or a combination of all (3). The basis of benign fibro-osseous lesions was established by Wladron in 1940 (7). They are divided into three main categories: fibrous dysplasia, reactive lesions (periapial cemento-osseous dysplasia, focal cemento-osseous dysplasia and florid cementoosseus dysplasia) and fibro-osseous neoplasms. Other synonyms used are epulis, peripheral fibroma with calcification, peripheral ossifying fibroma, Calcifying fibroblastic granulomas, and peripheral cemento-ossifying fibroma, peripheral cementifying fibroma, ossifying fibro-epithelial polyp, peripheral fibroma with osteogenesis, peripheral fibroma with cementogenesis (8).

Although the etiopathogenesis of PCOF is not clear, some investigators consider that the lesion arise from the cells of the periodontal ligament and it often associated to trauma or local irritation such as by dental plaque, masticatory forces (3). Multicentric PCOF is observed in genetic associated conditions like Nevoid basal cell carcinoma syndrome Multiple endocrine neoplasiatype II; Neurofibromatosis Gardner syndrome (9).

Furthermore, peripheral cemento-ossifying fibroma tends to occur in young adults and adolescents, and has female predilection. The peak prevalence ages ranges between 10 and 19 years (5). According to Cuisia and Brannon, the prevalence of this tumor in children aged 5 to 9 years is $10 \%(10 \%)$. With respect to race, there is a predominance in whites [71\%], compared to blacks [36\%] (11). In the present case, the patient was 24 year old female and the lesion occurred in mandibular anterior region. Plaque and calculus along with hormonal influences due to the patient's age and sex might have been the cause for the gingival growth. In this regards, exposure of inflamed gingiva to progesterone and estrogen from saliva and blood stream is thought to be a contributory factor (12). Few cases in the elderly have been reported to the date, for example studies by Bhasinet al (13), Dalghous et al (14).

PCOFclinically presents as a pedulatenculated or sessile nodular mass, which originates from interdental papilla, with broad base. PCOF is slow growing mass less than $2 \mathrm{~cm}$ in diameter as reported in present case although lesions greater than $2 \mathrm{~cm}$ are occasionally observed. Approximately, $60 \%$ of the PCOFs occur in the maxilla, with a predilection for the incisors and canine areas, in contrast to the anterior mandibular location of our case. Its color is similar to that of the mucosa unless the lesion is ulcerated and surface may be smooth or irregular. Pathological migration of tooth and bone destruction has been also reported but these are not common (8). These phenomena were not noted in the present case.

Radiographically, PCOF may follow different patterns depending on the amount of mineralized tissue, radio-opaque foci of calcification have been reported to be scattered through the central area of the lesion, but not all lesions exhibit these radiographic characteristics. Most lesions are not associated with bone destruction. In rare instances, superficial erosion of bone is noted $(5,8)$. Radiographic finding were non-contributory in the present case. 
Histologically, the lesion appears as nonencapsulated fibrous connective tissue with parakeratinzed stratified squamous epithelium of variable thickness with evidence of ulceration in some areas. Benign fibrous connective tissue with varying content of fibroblasts, myofibroblasts and collagen, sparse to profuse endothelial proliferation, mineralized material which may represent mature, lamellar or woven osteoid, cementum like material or dystrophic calcifications. Acute or chronic inflammation related findings can also be identified in lesions (5). Most of these features were reported in present case. This emphasizes the need for histopathological examination of biopsy specimen for an accurate diagnosis because of difficulty in diagnosing PCOF based only on clinical and radiographical observation.

Treatment requires thorough surgical excision of the lesion including the involved periosteum and the periodontal ligament. Meticulous oral prophylaxis and root scaling should be accomplished. PCOF recurs due to the incomplete removal of the lesion, the failure to eliminate local irritants, and difficulty in accessing the lesion during surgical manipulation as a result of the intricate location of the lesion (usually an interdental area) (8).

\section{CONCLUSION}

Peripheral Cemento-ossifying fibroma is slowly progressing, reactive lesion, growth of which is generally limited. It is possible to misdiagnose the PCOF from other reactive lesions which arise from gingival. So histopathologically investigation is important for accurate diagnosis and proper treatment of PCOF. A longer observation period is must because of high recurrence rate.

\section{REFERENCES}

1. Walters J.D., Will J. K., Hatfield R. D., Cacchillo D. A., Raabe D. A. Excision and repair of the peripheral ossifying fibroma: a report of 3 cases. J Periodontal. 2001; 72: 939-44.

2. Chang C. C., Hung H. Y., Chang J. Y., Yu C. H., Wang Y.P., Liu B.Y., et al. Central Ossifying Fibroma: A clinicopathologic study of 128 cases. J Formas Med Assoc. 2008; 107: 288-94.

3. Jayachandran S., Sachdeva S. CementoOssifying fibroma of mandible report of two cases. J Indian Acad Oral Med Radiol. 2010; 22: 53-56.

4. Poon C. K., Kwan P. C., Chao S. Y. Giant peripheral ossifying fibroma of the maxilla: report of a case. J Oral Maxillofac Surg. 1995; 53: 695-8.

5. Shah K., Kale A. D., Hallikerimath S., Chandra S. Peripheral cemento-ossifying fibroma: Report of a recurrence case. Contemp Clin Dent. 2012; 3: S23-S25.

6. Yadav R., Gulati A. Peripheral ossifying fibroma: a case report. J Oral Sci 2009; 51:151-4.

7. Waldron C. A. Fibro-osseous lesions of the jaws. J Oral Maxillofac Surg. 1993; 51: 828-35.

8. Verma E., Chakki A. B., Nagaral S. C., Ganji KK. Peripheral Cemento-Ossifying Fibroma: Case Series Literature Review. Case Reports in Dentistry. 2013; 1-5.

9. Jain A., Deepa D. Recurrence of peripheral ossifying fibroma: A case report. People's J Sci Res. 2010; 3: 23-5.

10. Cuisa Z. E., Brannon RB. Peripheral ossifying fibroma: A clinical evaluation of 134 pediatric cases. Pediatr Dent. 2001; 23: 245-8. 
11. Delbem A. C., Cunha R. F., Silva J. Institution in Nigeria. Niger Med J. 2011;52: Z, Soubhia A.M. Peripheral CementoOssifying Fibroma in Child. A Follow-Up of 4 Years. Report of a Case. Eur J Dent. 2008; 2:134-7.

12. Effiom O. A., Adeyemo W. L., Soyele OO. Focal reactive lesions of the Gingiva: An analysis of 314 cases at a tertiary Health $35-40$.

13. Bhasin M., Bhasin V., Bhasin A. Peripheral ossifying fibroma. Case Rep Dent 2013; 1-3. 14. Dalghous A., Alkhabuli J. O. Cementoossifying fibroma occurring in an elderly patient. A case report and a review of literature. Libyan J Med. 2007; 2: 95-8. 